\title{
ROLES OF ADDITIVES AND SURFACE CONTROL IN SLURRY ATOMIZATION
}

\author{
GRANT NO. DE-FG22-88PC88912 \\ FINAL PROJECT REPORT \\ $\mathrm{DOE} / \mathrm{PC} / 88912--\mathrm{T} 20$ \\ submitted \\ DE93 012262
}

to

The University Coal Research Program Pittsburgh Energy Technology Center

Department of Energy

by

Shirley C. Tsai, Professor and PI

Department of Chemical Engineering

California State University

Long Beach, CA 90840

(310)985-7534 (Phone)

(310)985-7561 (Fax)

\section{SUMMARY}

This project studies the rheology and airblast atomization of micronized coal slurries. Its major objectives are (1) to promote further understanding of the mechanisms and the roles of additives in airblast atomization of coal water slurry (CWS), and (2) to investigate the impacts of coal particle surface properties and interparticle forces on CWS rheology.

We have found that the flow behavior index (n) of a suspension (or slurry) is determined by the relative importance of the interparticle van der Waals attraction and the interparticle electrostatic repulsion. The interparticle attraction, measured by the Hamaker constant scaled to the thermal energy at $25^{\circ} \mathrm{C}(\mathrm{A} / \mathrm{kT})$, causes particle aggregation, which breaks down at high shear rates, and thus leads to slurry pseudoplastic behavior $(n<1)$. At a constant particle volume fraction and surface charge density (qualitatively measured by the zeta potential in deionized water), $\mathrm{n}$ decreases linearly as $\mathrm{A} / \mathrm{kT}$ increases. The relative viscosity of the pseudoplastic suspension with respect to that of the suspending liquid is found to be independent of particle density and correlate well with the particle Peclet number which equals the particle diffusional relaxation time multiplied by shear rate. Specifically, the relative viscosities of the pseudoplastic glycerol/water coal slurry and the ethylene glycol/glycerol sand slurry, at same volume fractions as well as similar particle size distributions and liquid viscosities, as functions of the particle Peclet number fall along the 


\section{DISCLAIMER}

This report was prepared as an accuunt of work sponsored by an agency of the United States Government. Neither the United States Government nor any agency thereof, nor any of their employees, makes any warranty, express or implied, or assumes any legal liability or responsibility for the accuracy, completeness, or usefulness of any information, apparatus, product, or process disclosed, or represents that its use would not infringe privately owned rights. Reference herein to any specific commercial product, process, or service by trade name, trademark, manufacturer, or otherwise does not necessarily constitute or imply its endorsement, recommendation, or favoring by the United States Government or any agency thereof. The views and opinions of authors expressed herein do not necessarily state or reflect those of the United States Government or any agency thereof. 
same line. Since particle diffusional relaxation time increases with particle radius cubed, larger particles in an aggregated system diffuse to a lesser extent than smaller particles within the same time scale of shear, and less energy is dissipated as a result.

We have developed a three-parameter model in terms of liquid-to-air mass ratio, the Weber number, and the Ohnersorge number for primary atomization based on the classical wave mechanism, momentum balance and energy considerations. The mass median diameters (MMDs) of atomized CWSs can be described by these models with correlation coefficients of 0.95 to 0.97 . We have also established that the effects of coal particle surface properties and additives on atomized drop sizes can be accounted for by their effects on slurry rheology.

Anionic dispersant concentration dictates the CWS rheology. As the concentration exceeds a threshold value, the interparticle electrostatic repulsion counter-balances the interparticle van der Waals attraction and, thus, the CWS becomes Newtonian at moderate to high shear rates. For example, as the anionic dispersant (Coal Master) increases in quantity from 0.15 to $1.35 \mathrm{wt} \%$ polymer on coal basis, the CWS of Upper Freeport coal at 0.55 volume fraction ( $62 \mathrm{wt} \%$ ) changes from a pseudoplastic behavior with a flow behavior index of 0.76 and a flow consistancy index of 20 (cgs units) to a Newtonian behavior with a viscosity of $2 \mathrm{P}$. The CWS of $0.15 \mathrm{wt} \%$ polymer has high shear viscosities (at prevailing atomization conditions) of 2.1 to $2.5 \mathrm{P}$. These two slurries have been atomized using a twin-fluid jet atomizer to drops with MMDs of 76 and $43 \mu \mathrm{m}$ at air-to-slurry mass ratios of 0.35 and 0.33 , respectively. Sedimentation testings show that the former slurry is stable with no settling for up to three weeks, but a soft packing forms at the bottom at the end of the fourth week. In contrast, the latter slurry settles easily.

\section{LIST OF MAJOR PUBLICATIONS (copies of reprints attached)}

1. S.C. Tsai and K. Ghazimorad, "Correlation Between the Hamaker Constant and the Flow Behavior Index of a Concentrated Suspension," J. of Rheology 34, 1327-1332, 1990.

2. S.C. Tsai and B. Viers, "Airblast Atomization of Viscous Liquids, "Fuel, 69, 1412-1419, 1990.

3. S.C. Tsai, K. Ghazimorad, and B. Viers, "Airblast Atomization of Micronized Coal Slurries Using a Twin-fluid Jet Atomizer," Fuel, 70, 483-440, 1991.

4. S.C. Tsai, K. Ghazimorad, B. Viers, and N. Widjaja, "Rheology and Atomization of Micronized Coal Water Slurries," Proc. of ASME 4th International Symposium on Solid Liquid Flow, FED 118, 123-130, 1991.

5. Q.Y. Song and S. C. Tsai, "Magnetic Seeding Flocculation of Weakly Magnetic Iron 
Minerals," Int. J. of Mineral Processing, 34, 219-229, 1992.

6. Tsai and Viers, "Airblast Atomization of Viscous Newtonian Liquids Using Twin-fluid Jet Atomizers of Various Designs," J. of Fluid Eng. 114, 113-118, 1992.

7. S.C. Tsai, D. Botts, and J. Plouff, "Effects of Particle Properties on the Rheology of Concentrated non-Colloidal Suspensions," J. of Rheology, 36, 1291-1305, 1992.

\section{STUDENT PARTICIPATION AND OUTCOME}

Three undergraduate students (Dale Botts, Brian Viers, and Khashayar Ghazimorad) who completed senior projects under my supervision with pariial support by the DOE have entered our MS in Engineering program, and continue research under my supervision. Botts completed his thesis and obtained a Master Degree in Engineering in October, 1992, and plans to obtain a Ph.D.. My other undergraduate students involved in this project are Nuragung Widjaja, Jon Peters, Paul Childs, and John Hecht. Widjaja has entered the graduate program in the University of Southern California. Paul Childs plans to enroll in our MS program. Jon Peters is working in an energy company and John Hecht is seriously considering graduate study.

\section{MAJOR NEW FINDINGS AND CONCLUSIONS}

A wide variety of particles ranging from monodispersed polystyrene spheres $\mathrm{P}_{2}$ and Upper Freeport Coal (Up1 and Up4) particles of irregular shape to polydispersed glass beads \#5000 and Pittsburgh Seam \#8 coal (Pgh) are used. The densities, volume mean diameter (VMD) and the mass median diameter (MMD) of the partilces used are listed in Tables I and II, and the coal analyses are given in Table II. Both nonaqueous and aqueous liquids and nonaqueous liquid mixtures with viscosities ranging from $1 \mathrm{cP}$ (water) to $10 \mathrm{P}$ (glycerol) are used as the suspending liquids. An anionic dispersant, Coal Master A23M from Henkel Corporation containing $44 \mathrm{wt} \%$ ammonium naphthalene sulfonate formaldehyde polymer, is used in the CWS preparation. While the detailed experimental methods and results are given in the attached copies of reprints, the major new findings and conclusions obtained in this project are given as follows:

\section{Slurry Rheology}

(1) The flow behavior index of a suspension is determined by the relative importance of the interparticle van der Waals attraction and the interparticle electrostatic repulsion. The interparticle attraction causes particle aggregation which breaks down at high shear rates and thus leads to slurry pseudoplastic behavior $(n<1)$. At a constant particle volume fraction and surface charge density (qualitatively measured by the zeta potential in deionized water), $\mathrm{n}$ decreases linearly as the nondimensional Hamaker constant $(\mathrm{A} / \mathrm{kT})$ increases as shown in 
Fig. 1. In this figure, the non- aqueous suspensions include polystyrene spheres, glass beads, and irregularly shaped sand particles suspended in silicone oils, ethylene glycol, glycerol, and mixtures of ethylene glycol and glycerol. The aqueous suspensions include coal particles suspended in mixtures of water and glycerol or ethylene glycol or i-propanol. Note that the Hamaker constant is calculated by the Lifshitz equation:

$$
A-\frac{3}{4} k T\left(\frac{\epsilon_{1}-\epsilon_{3}}{\epsilon_{1}+\epsilon_{3}}\right)^{2}+\frac{3 h v_{e}\left(n_{1}^{2}-n_{3}^{2}\right)^{2}}{16 \sqrt{2}\left(n_{1}^{2}+n_{3}^{2}\right)^{\frac{3}{2}}}
$$

where $h$ and $k$ are the Planck and Boltzman constants, respectively; $\epsilon_{1}$ and $\epsilon_{3}$ are, respectively, the dielectric constants of particle and the suspending liquid; $n_{1}$ and $n_{3}$ are the corresponding refractive indices; $v_{\mathrm{e}}$ is the absorption frequency. The Hamaker constant of solid suspended in a liquid mixture is assumed to be the sum of those of solid in pure liquids multiplied by the liquid volume fractions [Tsai and Ghazimorad, 1990].

(2) Both Fig. 2 and Fig. 3 show that the relative viscosity $\left(\eta_{r}\right)$ of the pseudoplastic suspension with respect to that of the suspending liquid $\left(\eta_{0}\right)$ correlates well with the particle Peclet number which equals the time required for a particle to diffuse a distance comparable to its average radius $(\bar{a})$ multiplied by shear rate $(\dot{\gamma})$. The relative suspension viscosity is also shown in these figures to be independent of particle density [Tsai, Botts and Plouff, 1992]. Specifically, the relative viscosities as functions of particle Peclet number for the 0.45 volume fraction slurries of Upper Freeport (Up1 and Up4) coal in 74/26 wt/wt of glycerol/water and sand in 80/20 wt/wt of ethylene glycol/glycerol fall along the same curve. The corresponding curves for Illinois \#6 coal (ILL) and for Pittsburgh Seam \#8 (Pgh) coal lie slightly above and far below as shown in Fig. 3, respectively. This finding may be attributed to the slightly narrower size distribution of the ILL coal and much broader size distribution of the Pgh coal as compared to the Upper Freeport Up1 and Up4 coals as shown in Fig. 4.

(3) While the flow behavior index of a concentrated suspension is independent of the shape of particles with aspect ratios close to unity, its relative viscosity is strongly influenced by the particle shape. Presence of irregularly shaped particles results in reduction in the maximum particle packing fraction. Therefore, a suspension of irregulary shaped particles has a higher relative viscosity than one of spherical particles of the same volume fraction. Using the maximum packing fraction $\left(\varphi_{M}\right)$ as the sole parameter which accounts for the effects of particle shape and size distribution, the Krieger-Dougherty rigid sphere model of colloidal suspensions satisfactorily depicts the relative viscosity of a Newtonian noncolloidal suspension as a function of particle volume fraction $(\varphi)$ as shown in Fig. 5. This maximum packing fraction $\left(\varphi_{M}\right)$ is in very good agreement with the maximum volume fraction obtained by sedimentation. Note that the intrinsic viscosity $[\eta]$ is taken as 2.67 in the rigid sphere model: 


$$
\eta_{\mathrm{r}}=\left(1-\varphi / \varphi_{\mathrm{M}}\right)^{-[\eta] \varphi_{\mathrm{M}}}
$$

[Tsai, Botts and Plouff, 1992].

(4) Coal dispersant concentration predominates the CWS rheology. Less quantity is required for the lower ranking Pgh and ILL coals than the higher ranking Upper Freeport coal to form Newtonian slurries at moderate rates (above $100 \mathrm{~s}^{-1}$ ). Nevertheless, as shown in Table III, the relative viscosities of Newtonian CWSs using both Upper Freeport and Pittsburgh Seam coals and anionic dispersant A23M are an order of magnitude higher than those predicted by the Krieger-Dougherty rigid sphere model with the intrinsic viscosity $[\eta]$ equaling 2.67 and the maximum packing fraction determined from sedimentation.

\section{Airblast Atomization of Viscous Liquids and Micronized Coal Slurries}

(1) The twin-fluid jet atomizer whose dimensions are given in Table IV is designed to minimize errosion of the nozzle tip. As shown in Fig. 6, the slurry passes axially through the center of the distributor. The atomizing air passes through the $15^{\circ}$-angled slits drilled in the $45^{\circ}$ taper of the distributor and, thus, swirls around the slurry jet. The nozzle has a single discharge port of diameter larger than the diameter of the distributor for slurry passage. As shown in Table $\mathrm{V}$, atomized drops obtained by $15^{\circ}$ swirl (distributor \#1) are significantly smaller than those by $5^{\circ}$ swirl (distributor \#3) [Tsai and Viers, 1992].

Also shown in Table $\mathrm{V}$, the atomized drop sizes substantially decrease as the atomizing air pressure exceeds a threshold value which varies from less than 170 to $220 \mathrm{kPa}$ depending on the nozzle diameters [Tsai and Viers, 1990; Tsai and Viers, 1992].

(2) While pseudoplasticity plays a significant role in atomization, the high shear viscosity dictates the atomized drop sizes. The atomized drop sizes, represented by the mass median diameter scaled to an atomizer characteristic length $\left(\mathrm{MMD} / \mathrm{L}_{\mathrm{c}}\right)$, can be described in terms of three nondimensional groups, namely, slurry-to-air mass ratio $\left(\dot{M}_{S} / \dot{M}_{A}\right)$, the Weber number (We), and the Ohnesorge number $(\mathrm{Z})$ :

$$
\mathrm{MMD} / \mathrm{L}_{\mathrm{c}}=\left(1+\mathrm{M}_{\mathrm{S}} / \mathrm{M}_{\mathrm{A}}\right)\left\{\mathrm{x} 2 \cdot \mathrm{We} \mathrm{e}^{-\mathrm{x} 1}+\mathrm{x} 3 \cdot \mathrm{Z}^{\mathrm{j} \cdot \times 1}\right\}
$$

where $\mathrm{j}=1$ or 2 , We equals the ratio of aerodynamic force to surface tension and $\mathrm{Z}$ represents the viscous effect. This model is based on the classical wave mechanism, momentum balance, and energy considerations. The three parameters (xi, i= 1 to 3 ) are determined by the best least square fit of the model to the experimental results using the iterative generalized inverse method. As shown in Table VI, the exponents of the $\mathrm{We}^{-1}$ - and Z- dependencies fall between the values, $2 / 3$ and $1 / 3$, predicted by the acceleration and the capillary wave mechanisms, respectively. Very good agreement (see Fig. 7) has been 
obtained between the model and the experimental drop MMDs [Tsai and Viers, 1990; Tsai and Viers, 1992].

(3) Both Newtonian and pseudoplastic CWSs of Upper Freeport coal (Up3 with $12.5 \mu \mathrm{m}$ MMD and $17.8 \mu \mathrm{m} \mathrm{VMD)}$ at 0.55 volume fraction (62 wt \%) have been prepared through use of an anionic dispersant (Coal Master) alone in quantities ranging from 0.15 to $1.35 \mathrm{wt} \%$ polymer on coal basis. The CWS of $0.15 \mathrm{wt} \%$ polymer has a flow behavior index of 0.76 and high shear viscosities (at prevailing atomization conditions) of 2.1 to $2.5 \mathrm{P}$. The CWS of 1.35 wt\% polymer is Newtonian with a viscosity of $2 \mathrm{P}$. These two slurries have been atomized using a twin-fluid jet atomizer to drops with MMDs of 76 and $43 \mu \mathrm{m}$ at air-to-slurry mass ratios of 0.35 and 0.33 , respectively. Sedimentation testings show that the former slurry is stable for one month. 
TABLE I. Particles Sizes and Densities

\begin{tabular}{llll} 
Particle & VMD, $\mu \mathrm{m}$ & MMD, $\mu \mathrm{m}$ & Density, g/cc \\
\hline Polystyrene $\mathrm{P}_{1}$ & 77.8 & 72 & 1.05 \\
Polystyrene $\mathrm{P}_{2}$ & 6.0 & 5.5 & 1.05 \\
Glass bead \#4000 GL1 & 30.5 & 29 & 2.39 \\
Glass bead \#5000 GL4 & 22.6 & 20.9 & 2.39 \\
Glass bead 20-40 $\mu \mathrm{m}^{*}$ GL5 & 24.2 & 15.8 & 2.39 \\
Sand 20-40 $\mu \mathrm{m}^{*}$ & -- & -- & 2.50 \\
Sand, <63 $\mu \mathrm{m}$, unsieved & -- & -- & 2.50 \\
Upper Freeport coal & 4.4 & 4.4 & 1.33 \\
Illinois \#6 coal & 7.8 & 3.7 & 1.37 \\
\end{tabular}

*Sieved to 20-40 $\mu \mathrm{m}$ using the Alpine Air-jet Siever

Table II. COAL ANALYSES

\begin{tabular}{llllll}
$\begin{array}{l}\text { Analysis } \\
\text { Dry basis }\end{array}$ & $\begin{array}{l}\text { Upper } \\
\text { Up2 }\end{array}$ & $\begin{array}{l}\text { Freeport } \\
\text { Up3 }\end{array}$ & $\begin{array}{l}\text { Coal } \\
\text { Up1 \& Up4 }\end{array}$ & $\begin{array}{l}\text { Pittsburgh } \\
\text { Seam, Pgh Illinois \#6 }\end{array}$ \\
\hline Volatile, \% & 23.1 & 25.2 & 28.4 & 42.4 & 40.6 \\
& & & & & \\
Ash, \% & 16.7 & 9.1 & 5.4 & 3.9 & 4.2 \\
Carbon, \% & 72.1 & 81.1 & 82.8 & 78.4 & 75.2 \\
Hydrogen, \% & 4.5 & 5.1 & 5.1 & 5.4 & 5.2 \\
Nitrogen, \% & 1.3 & 1.4 & 0.7 & 1.4 & 1.4 \\
Oxygen, \% & 5.5 & 3.3 & 4.8 & 7.9 & 11.5 \\
Sulfur, \% & 0.7 & 0.6 & 1.2 & 3.1 & 2.5 \\
& & & & & \\
Particle size & & & & & \\
MMD, $\mu \mathrm{m}$ & 10 & 12.5 & 4.0 & 9.2 & 7.8 \\
VMD, $\mu \mathrm{m}$ & 15.8 & 17.8 & 4.9 & 12.9 & 9.9 \\
& & & & & \\
\hline
\end{tabular}


TABLE III. Newtonian CWSs Using Anionic Dispersant A23M

\begin{tabular}{|c|c|c|c|c|c|c|c|}
\hline \multirow{3}{*}{$\begin{array}{l}\text { A23M Concentratio } \\
\text { wt } \% \text { of Coal }\end{array}$} & \multirow{3}{*}{$\frac{\text { Volume }}{0.48}$} & \multirow{2}{*}{\multicolumn{2}{|c|}{$\begin{array}{l}\text { Coal Loading } \\
\text { Fraction wt } \%\end{array}$}} & \multirow{3}{*}{$\begin{array}{l}\text { Shear Rate } \\
\mathrm{s}^{-1} \\
250-1500\end{array}$} & \multicolumn{3}{|c|}{ Relative Viscosity } \\
\hline & & & & & Measured & Predic & $\varphi_{M}{ }^{b)}$ \\
\hline & & UP1 & 54 & & 1150 & 162 & 0.49 \\
\hline 1.15 & 0.45 & UP1 & 52 & $250-5000$ & 450 & 27 & 0.49 \\
\hline 1.15 & 0.45 & UP1 & 52 & $\left.100-750^{c}\right)$ & 450 & 27 & 0.49 \\
\hline 1.20 & 0.43 & UP1 & 50 & $500-5000$ & 300 & 16 & 0.49 \\
\hline 1.73 & 0.50 & UP2 & 57 & $700-6000$ & 160 & 17.6 & 0.60 \\
\hline 0.75 & 0.55 & UP3 & 62 & $500-6000$ & 200 & 32 & 0.63 \\
\hline 0.36 & 0.55 & UP3 & 62 & $500-8000$ & 205 & 32 & 0.63 \\
\hline 1.35 & 0.55 & UP3 & 62 & $500-8000$ & 215 & 32 & 0.63 \\
\hline 0.38 & 0.40 & $\mathrm{Pgh}$ & 48 & $\left.150-440^{d}\right)$ & 43 & 6 & 0.59 \\
\hline 0.36 & 0.45 & Pgh & 53 & $4000-8000$ & 145 & 9.7 & 0.59 \\
\hline 0.61 & 0.45 & Pgh & 53 & $\left.25-440^{d}\right)$ & 165 & 9.7 & 0.59 \\
\hline 0.38 & 0.49 & Pgh & 57 & $200-1300$ & 520 & 16.5 & 0.59 \\
\hline 0.37 & 0.52 & Pgh & 60 & $1000-4500$ & 1520 & 29 & 0.59 \\
\hline
\end{tabular}

a) Predicted by the Krieger-Dougherty Equation with intrinsic viscosity [ $\eta$ ] equaling 2.67 .

b) Determined from sedimentation except 0.59 estimated for Pittsburgh \#8 coal (Pgh).

c) The aqueous solution contains $35 \mathrm{wt} \%$ glycerol.

d) Measured with Haake rotational rheometer RV2. 
TABLE IV. Atomizer Dimensions

$\begin{array}{lll}\begin{array}{l}\text { Nozzle tip } \\ \text { No. }\end{array} & \begin{array}{l}\text { Discharge Diameter } \\ \underline{\mathrm{cm}}\end{array} & \begin{array}{l}\text { Cross Section } \\ \underline{\mathrm{cm}^{2}}\end{array} \\ 1 & 0.249 & 4.866 \times 10^{-2} \\ 2 & 0.178 & 2.483 \times 10^{-2} \\ 3 & 0.305 & 7.306 \times 10^{-2}\end{array}$

\begin{tabular}{|c|c|c|c|c|}
\hline \multirow{2}{*}{\multicolumn{2}{|c|}{$\begin{array}{l}\text { Distributor* } \\
\text { No. Dia. cm } \\
\end{array}$}} & \multirow{2}{*}{$\begin{array}{l}\text { Slit Design } \\
\text { No.-cm x cm -deg. }\end{array}$} & \multicolumn{2}{|c|}{ Cross Section, $\mathrm{cm}^{2}$} \\
\hline & & & Liquid & $\underline{\text { Air }}$ \\
\hline 1 & 0.152 & $6-0.16 \times 0.097-15$ & $1.815 \times 10^{-2}$ & $9.312 \times 10^{-2}$ \\
\hline 2 & 0.152 & $4-0.24 \times 0.076-15$ & $1.815 \times 10^{-2}$ & $7.354 \times 10^{-2}$ \\
\hline 3 & 0.152 & $6-0.16 \times 0.097-5$ & $1.815 \times 10^{-2}$ & $9.312 \times 10^{-2}$ \\
\hline 47 & 0.244 & $6-0.086 \times 0.114-15$ & $4.676 \times 10^{-2}$ & $5.925 \times 10^{-2}$ \\
\hline
\end{tabular}

*Diameter of the central opening for liquid flow \#Variflo atomizer by Delavan Corp., South Carlorina 
TABLE V. Effect of Slit Angle on Glycerol Atomization Using Nozzle \#1

\begin{tabular}{llllll}
$\begin{array}{l}\text { Dtr. } \\
\text { No. }\end{array}$ & $\begin{array}{l}\text { Slit } \\
\text { Angle } \\
\text { deg. }\end{array}$ & $1+\mathrm{M}_{\mathrm{L}} / \mathrm{M}_{\mathrm{A}}$ & $\begin{array}{c}\mathrm{P}_{\mathrm{A}} \\
\mathrm{kPa}\end{array}$ & $\mathrm{We}$ & $\mathrm{MMD}$ \\
\hline 1 & 15 & 1.76 & 211 & 263 & $40(79)^{*}$ \\
1 & 15 & 1.72 & 177 & 278 & 85 \\
3 & 5 & 1.93 & 177 & 241 & $131(89)^{*}$ \\
3 & 5 & 1.76 & 177 & 249 & $121(81)^{*}$ \\
\hdashline & & & & & \\
1 & 15 & 2.09 & 218 & 278 & $54(94)^{*}$ \\
1 & 15 & 2.28 & 170 & 197 & 93 \\
3 & 5 & 2.33 & 149 & 202 & $174(109)^{*}$
\end{tabular}

* Values calculated using the following equation for atomization at inlet air pressures below the threshold pressure:

$\mathrm{MMD} / \mathrm{L}_{\mathrm{c}}=\left(1+\mathrm{M}_{\mathrm{L}} / \dot{\mathrm{M}}_{\mathrm{A}}\right)\left\{8.5 \cdot \mathrm{We} \mathrm{e}^{-0.47}+1.4 \mathrm{Z}^{0.47}\right\} \cdot 10^{-2}$

where $L_{c}$ equals $0.152 \mathrm{~cm}$. 
TABLE VI. Semi-empirical Model for Airblast Atomization of Micronized Coal Slurries and Viscous Liquids with viscosities up to $10 \mathrm{P}$

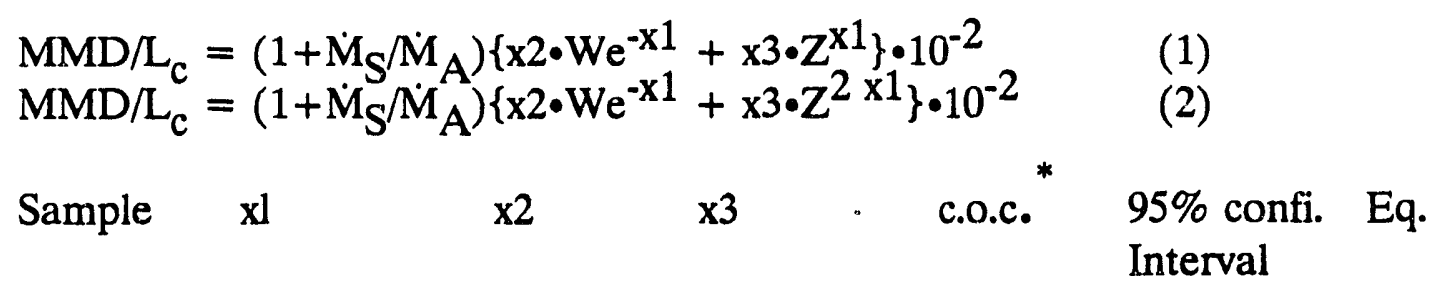

Glycerol $\quad 0.47 \pm 0.04 \quad 7.9 \pm 0.8 \quad 1.38 \pm 0.14 \quad 0.94$ (a) $\quad 0.88-0.97$ $0.60 \pm 0.04 \quad 12.0 \pm 1.0 \quad 1.10 \pm 0.04 \quad 0.93$ (b) $\quad 0.87-0.97$

$\begin{array}{lllll}0.30 \pm 0.02 & 5.0 \pm 0.5 & 1.0 \pm 0.1 & 0.94 \text { (a) } & 0.88-0.97 \\ 0.38 \pm 0.03 & 6.0 \pm 0.6 & 0.80 \pm 0.03 & 0.93 \text { (b) } & 0.87-0.97\end{array}$

\begin{tabular}{|c|c|c|c|c|c|}
\hline CWS & $\begin{array}{l}0.39 \pm 0.02 \\
0.36 \pm 0.01\end{array}$ & $\begin{array}{l}13.5 \pm 0.9 \\
12.0 \pm 0.4\end{array}$ & $\begin{array}{l}1.90 \pm 0.06 \\
0.23 \pm 0.02\end{array}$ & $\begin{array}{l}0.96 \text { (a) } \\
0.97 \text { (b) }\end{array}$ & $\begin{array}{c}0.90-0.98 \\
0.94-0.99\end{array}$ \\
\hline & $\begin{array}{l}0.30 \pm 0.02 \\
0.37 \pm 0.01\end{array}$ & $\begin{array}{l}11.5 \pm 0.9 \\
13.3 \pm 0.6\end{array}$ & $\begin{array}{l}1.26 \pm 0.02 \\
0.17 \pm 0.02\end{array}$ & $\begin{array}{l}0.95 \text { (a) } \\
0.97 \text { (b) }\end{array}$ & $\begin{array}{l}0.87-0.98 \\
0.94-0.99\end{array}$ \\
\hline
\end{tabular}

* Coefficient of correlation

(a) Atomization at air pressures below a threshold value

(b) Atomizing air pressure above the threshold value, MMD is replaced by VMD in the case of glycerol atomization 


\section{List of Figures}

Fig. 1 Correlation between the flow behavior index of a concentrated suspension and the Hamaker constant (solid circles are data from Gadala-Maria and Acrivos, 1980 at volume fractions $(\varphi$ 's) of $0.55,0.45$, and 0.40 )

Fig. 2 Comparisons of the relative viscosities of coal water slurries with sand suspension and polystyrene suspensions with glass bead suspensions

Fig. 3 Comparisons of the relative viscosities of the Upper Freeport (Up1 and Up4), Pittsburgh Seam \#8 (Pgh), and Illinois \#6 (ILL) coal slurries

Fig. 4 Paticle size distributions of Upper Freeport, Pittsburgh Seam Illinois \#6 coals, and sieved sand.

Fig. 5 Comparison of the experimental Newtonian limits of the relative viscosity of concentrated suspensions of polystyrene spheres $P_{1}$ (solid circles), the experimental relative viscosities of the concentrated Newtonian suspensions of glass beads $\# 4000$ (GL1, 85\% spherical, open diamonds), and irregularly shaped sand (triangles)

Fig. 6 Design of a twin-fluid jet atomizer

Fig. 7 Correlation between the wave mechanism based-models and the measured nonijimensional drop MMDs of atomized micronized coal slurries at atomizing air pressures a) below and b) above the threshold pressure (diagonal lines represent perfect correlation) 
Fig. 1 Correlation between the flow behavior index of a concentrated suspension and the Hamaker constant (solid circles are data from Gadala-Maria and Acrivos, 1980 at volume fractions ( $\varphi$ 's) of $0.55,0.45$, and 0.40 )

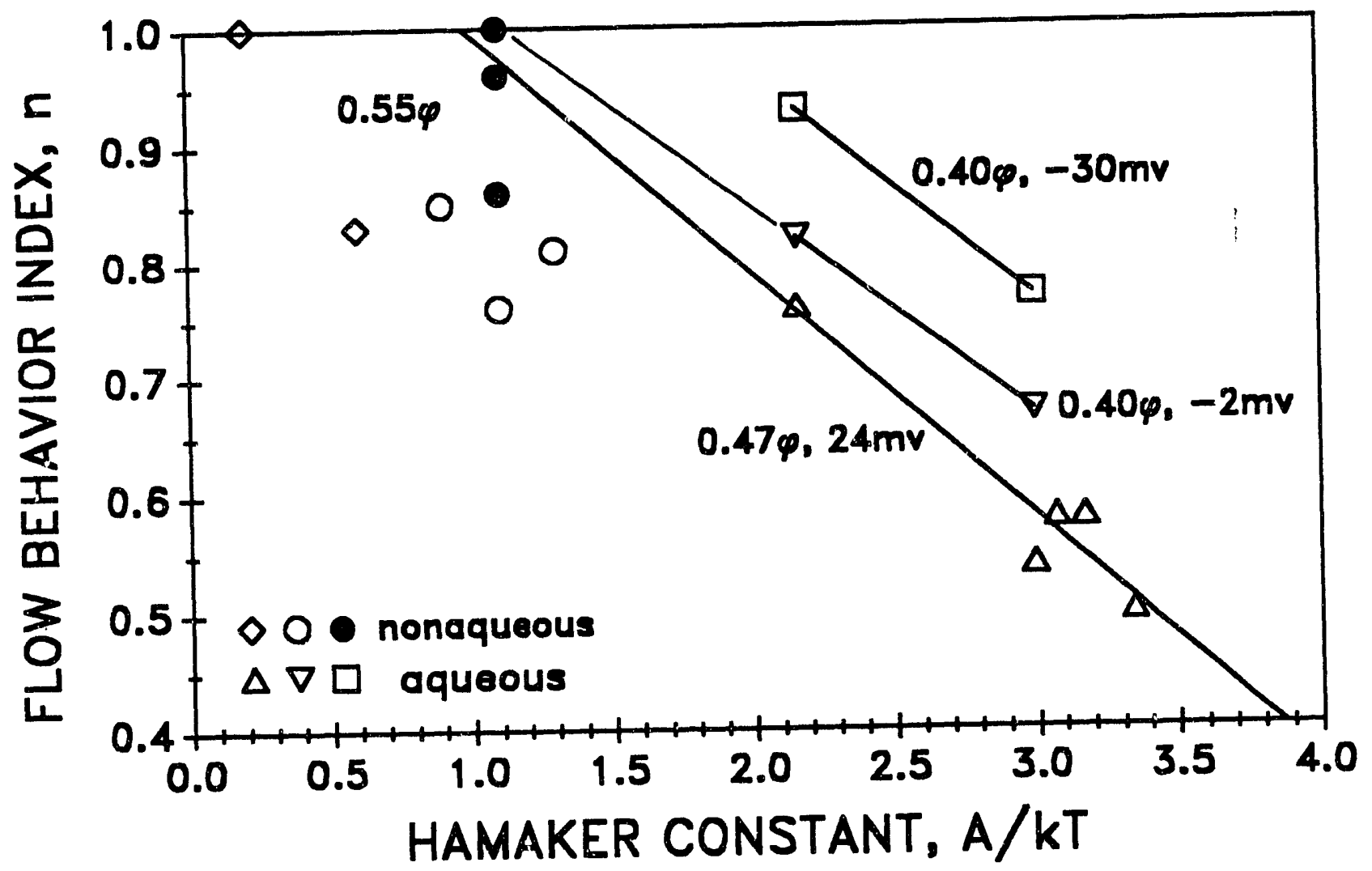


Fig. 2 Comparisons of the relative viscosities of coal water slurries with sand suspension and polystyrene suspensions with glass bead suspensions

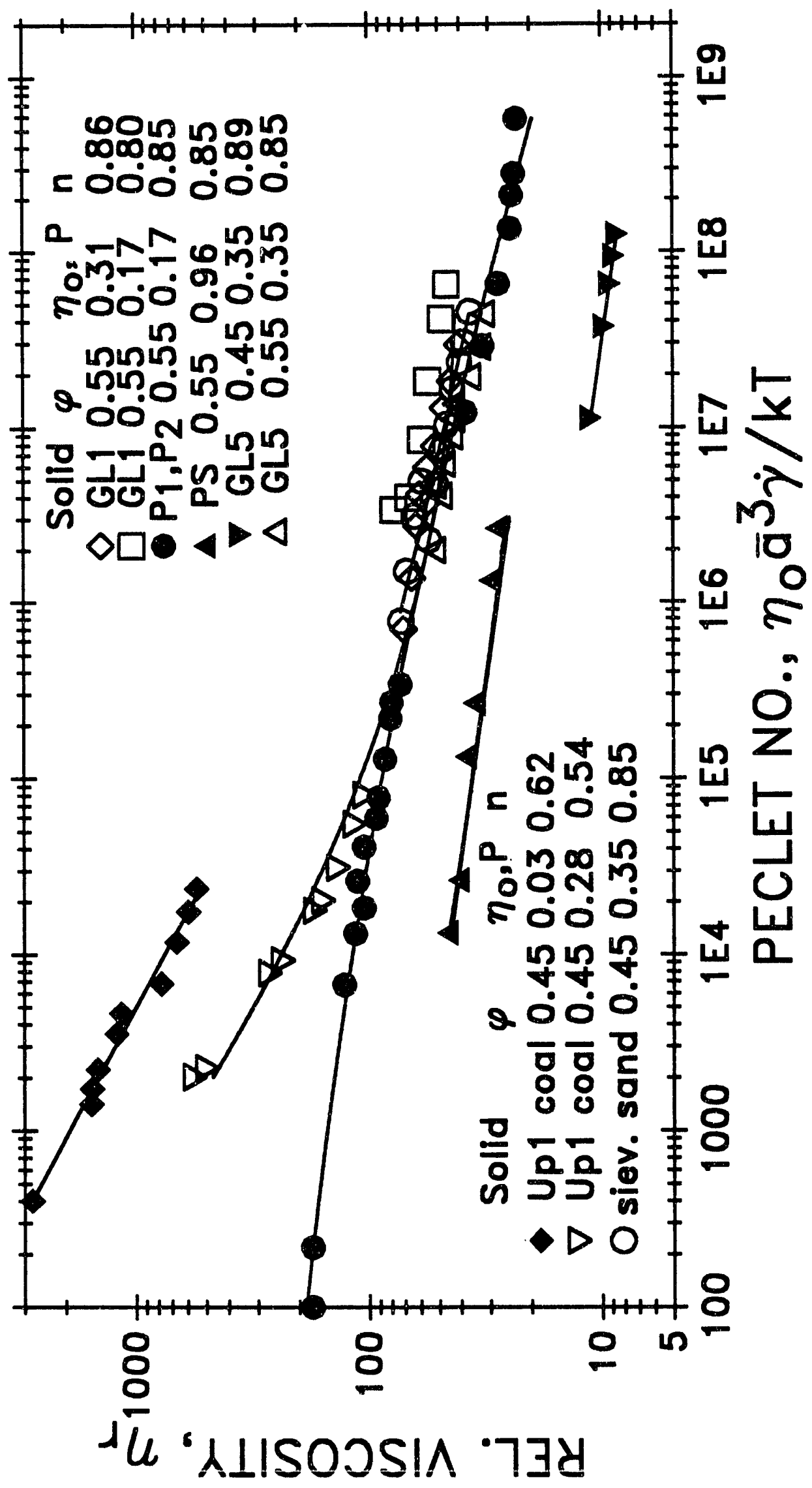


Fig. 3 Comparisons of the relative viscosities of the Upper Freeport (Up1 and Up4), Pittsburgh Seam \#8 (Pgh), and Illinois \#6 (ILL) coal slurries

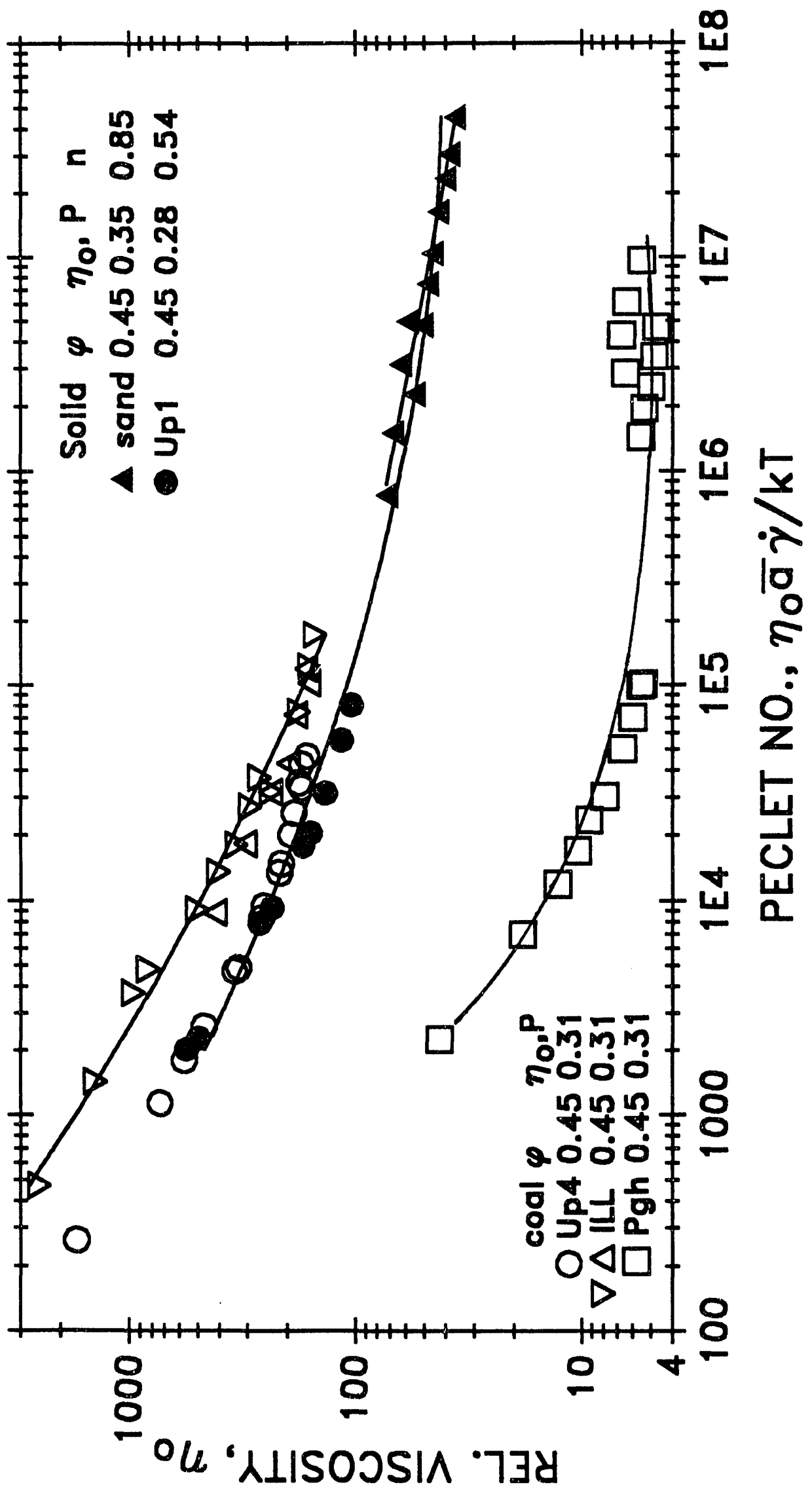


Fig. 4 Paticle size distributions of Upper Freeport, Pittsburgh Seam Illinois \#6 coals, and sieved sand.

3

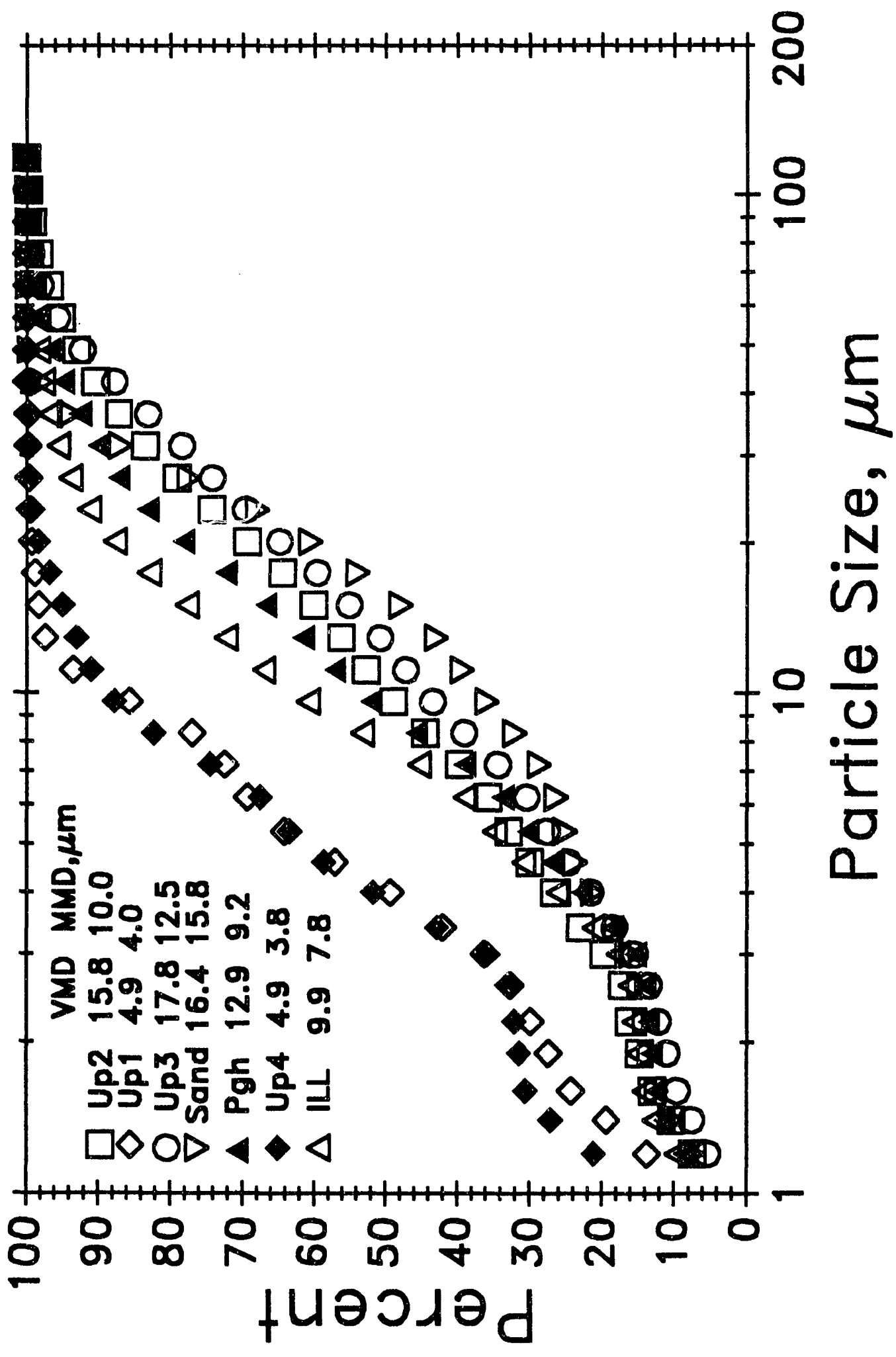


Fig. 5 Comparison of the experimental Newtonian limits of the relative viscosity of concentrated suspensions of polystyrene spheres $\mathrm{P}_{1}$ (solid circles), the experimental relative viscosities of the concentrated Newtonian suspensions of glass beads \#4000 (GL1, 85\% spherical, open diamonds), and irregularly shaped sand (triangles)

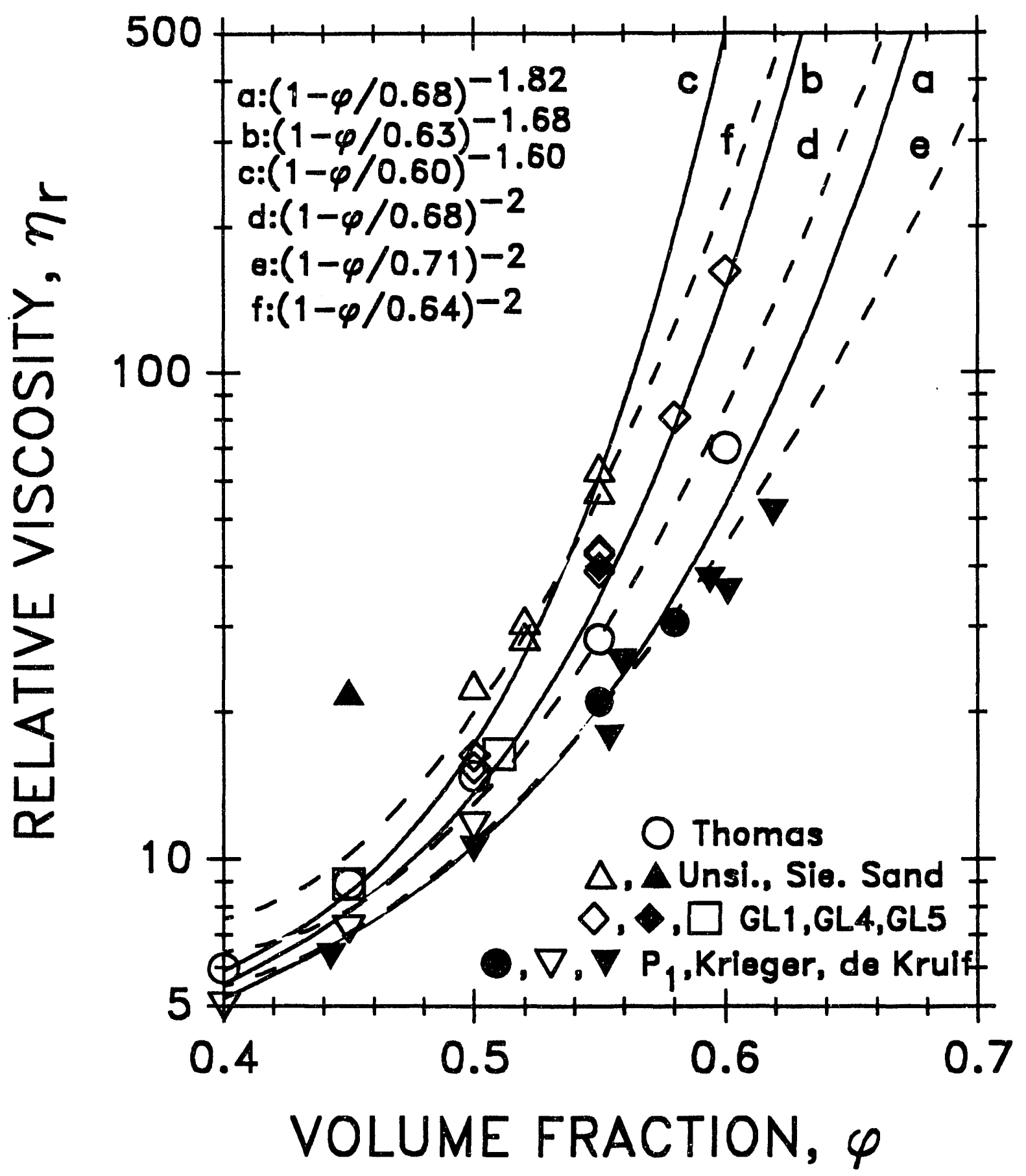


Fig. 6 Design of a twin-fluid jet atomizer

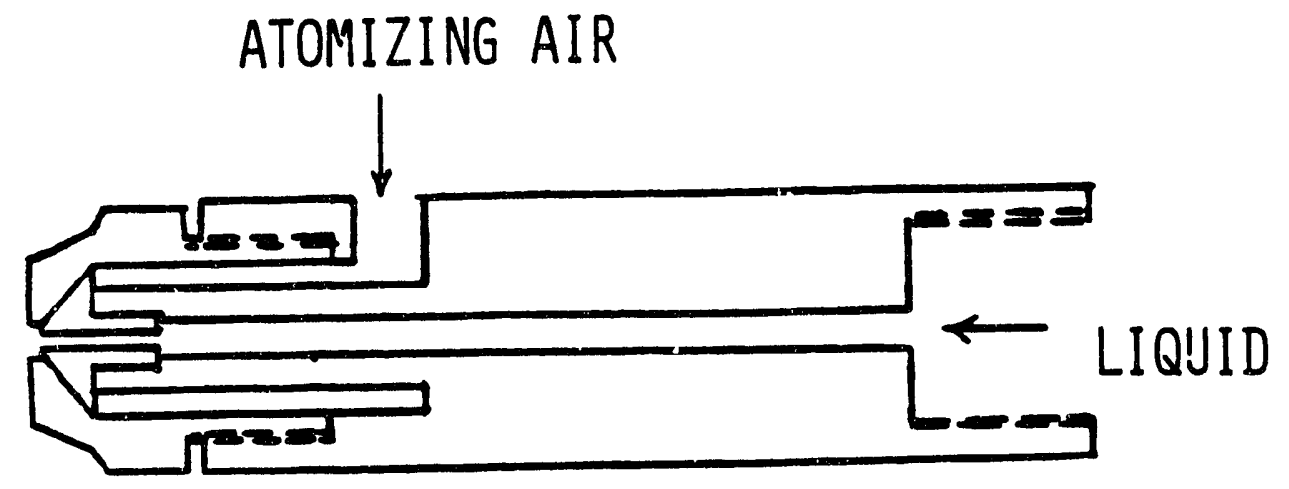

DISTRIBUTOR END VIEW

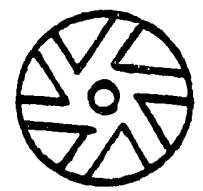


Fig. 7 Correlation between the wave mechanism based-models and the measured nondimensional drop MMDs of atomized micronized coal slurries at atomizing air pressures a) below and b) above the threshold pressure (diagonal lines represent perfect correlation)
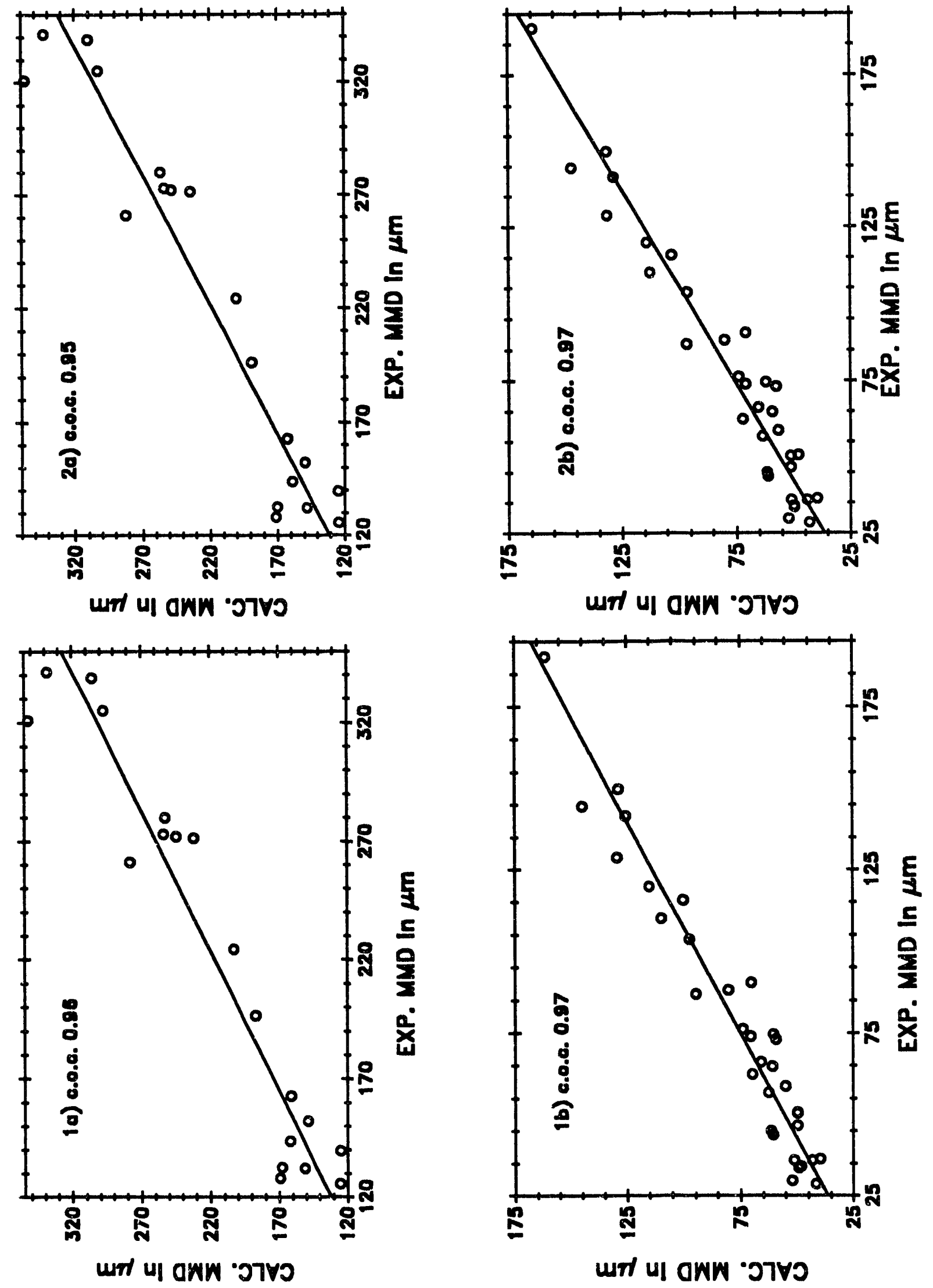

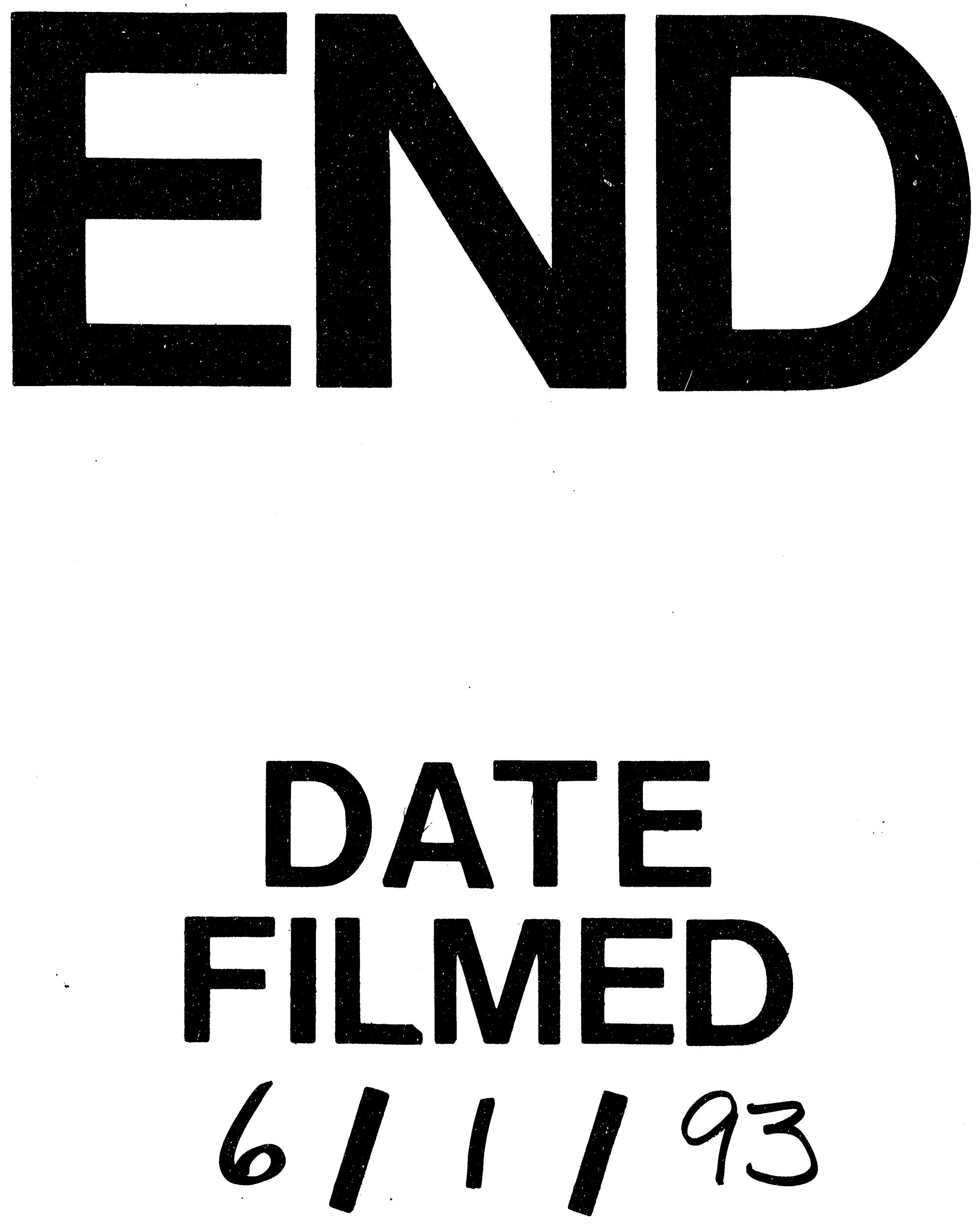
